\title{
Uptake of minimum acceptable diet among children aged 6-23 months in orthodox religion followers during fasting season in rural area, DEMBECHA, north West Ethiopia
}

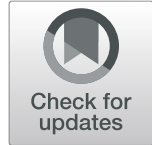

Efram Mulat ${ }^{1}$, Girma Alem², Wubetu Woyraw ${ }^{3^{*}}$ and Habtamu Temesgen ${ }^{1}$

\begin{abstract}
Background: Under-nutrition is the cause for poor physical and mental development and has more burden among infants and young children aged between 6 and 23 months. Cultural practices like not providing animal source foods for infants and young child aged between 6 and 23 months were barrier for practicing proper children feeding. The aim of this study was to assess minimum acceptable diet and associated factors among children aged between 6 and 23 months in Orthodox religion during fasting season in rural area, Dembecha, Ethiopia.

Methods: A community-based cross-sectional study was conducted to assess Minimum Acceptable diet. Random sampling technique was applied to select 506 study participants. Interview was used to collect data on Practice of minimum acceptable diet, minimum dietary diversity, minimum meal frequency and related factors among children aged between 6 and 23 months from mothers / caregivers.

Result: About 8.6\% of infants and young children aged between 6 and 23 months received minimum acceptable diet. Education status of mother(AOR $=0.22,95 \% \mathrm{Cl}: 0.1,0.48)$, involvement of mother in decision making ( $\mathrm{AOR}=0.22,95 \% \mathrm{Cl}: 0$. 10,0.48), birth order of index children ( $\mathrm{AOR}=0.36,95 \% \mathrm{Cl}: 0.14,0.94)$, knowledge on feeding frequency $(\mathrm{AOR}=0.3,95 \% \mathrm{Cl}: 0$. 16,0.58), and institutional delivery ( $\mathrm{AOR}=5.13,95 \% \mathrm{Cl}: 1.26,20.80$ ) were significantly associated with minimum acceptable diet.

Conclusion: Minimum acceptable diet practice was low. Educational status of mother, involvement of mother in decision making, knowledge on feeding frequency and institutional delivery were significantly associated with minimum acceptable diet. This indicates that nutrition education and counseling related to infant and young child feeding practice is not addressed for all mothers. Strengthening mothers' education on acceptable child feed practice, and working with religion leaders to increase knowledge of mothers on child feed practice are recommended.
\end{abstract}

Keywords: Minimum acceptable diet, Fasting, Orthodox, Dietary diversity, Meal frequency

\section{Background}

Inappropriate feeding practice of Infants and young child leads to malnutrition, this exposes the children to under nutrition, increasing morbidity and mortality, and chronic stunting that will be continuing to next generations [1-3]. By improving the quality and frequency of complementary

\footnotetext{
* Correspondence: wubetu662@gmail.com

${ }^{3}$ Lecturer of Nutrition, Department of Human Nutrition and Food Sciences, College of Health Science, Debre Markos University, P.O. Box 269 Debre Markos, Ethiopia

Full list of author information is available at the end of the article
}

feeding practice it is possible to improve health, reducing morbidity and mortality of young children [4]. Nearly one third of children deaths could be prevented by appropriate complementary feeding practices $[5,6]$. Early initiation of breastfeeding, exclusive breastfeeding, implementing complementary feeding, consumption of diversified diet, adequate meal frequency, and consumption of iron fortified foods are core indicators for monitoring feeding practices of infants and children. Minimum Acceptable diet defined by $\mathrm{WHO}$ as is the proportion of children 6-23 months of age who receive a minimum acceptable diet (both

(c) The Author(s). 2019 Open Access This article is distributed under the terms of the Creative Commons Attribution 4.0 International License (http://creativecommons.org/licenses/by/4.0/), which permits unrestricted use, distribution, and reproduction in any medium, provided you give appropriate credit to the original author(s) and the source, provide a link to the Creative Commons license, and indicate if changes were made. The Creative Commons Public Domain Dedication waiver (http://creativecommons.org/publicdomain/zero/1.0/) applies to the data made available in this article, unless otherwise stated. 
minimum dietary diversity and the minimum meal frequency) during the previous $24 \mathrm{~h}[6,7]$.

In developing countries including Ethiopia, feeding infants and children with diversified diet is practiced inappropriately. In Africa less than one-third and one-half of children aged between 6 and 23 months met the minimum criteria for dietary diversity and meal frequency, respectively. That is why the prevalence of stunting in African countries increases threefold during the first 2 years of life [8].

Burden of stunting is high in Amhara region and children in rural are more vulnerable for stunting than urban children $[9,10]$. Minimum dietary diversity practice is low in Amhara region than national i.e., 2\% of children in Amhara region got minimum dietary diversity. Children of Orthodox mother were $40 \%$ less likely to receive minimum dietary diversity than non-Orthodox children [11]. In our country, especially in rural area, there is poor practice in children feeding $[9,12]$.

Around 50- $7 \%$ of death in under-five children in Ethiopia is accounted by inappropriate complementary feeding practices [4]. Malnutrition below 2 years of age leads children to become vulnerable to growth retardation, delayed mental development, micronutrient deficiencies, and common childhood illnesses and death. [13]. Culture has effect on practice of dietary diversity, meal frequency and minimum acceptable diet.

According to Ethiopian demographic health survey data analysis, consumption of animal source by orthodox religion followers children were less than other religion follower families [11].

Both minimum dietary diversity and meal frequency practices were affected by age of a child, birth order of index child, religion, and media exposure of mother. Minimum dietary diversity separately affected by educational level of a mother, residence and home gardening activity while mother's involvement in household decision making and postnatal visit have significant association with minimum meal frequency [11, 12, 14-20].

Minimum acceptable diet indicator is used for assessing infant and young child feeding practices and it is a composite indicator comprises minimum dietary diversity and minimum meal frequency indicators and to measure both quality and quantity of nutrients $[5,7]$. A cross- sectional study conducted in primary health care facility in 2015 to assess magnitude of minimum acceptable diet in Indonesia found that $66.6 \%$ of infants and young children aged 6-23 months consume minimum diversified diet [21]. A community- based cross-sectional study conducted in 2016 among rural resident in Nigerian Infant and Young Children (IYC) showed that 31.5\% infants consumed the minimum dietary diversity. [22].

Another community-based cross-sectional study conducted in southern part of Ethiopia (Arsi Zone) in 2015 showed that only $18.8 \%$ of children aged between 6 and 23 months consumed four or more food groups to meet the minimum dietary diversity criteria [23]. A health institution based cross sectional-study conducted in Addis Ababa in 2016 showed that $59.9 \%$ of the children aged 6-23 months meet the minimum requirement of diversified diet [15].

A cross-sectional study done to assess dietary diversity and meal frequency feeding practice in wailayita sodo town in 2015 showed that only $27.3 \%$ of infants and young children consumed diversified diet [24]. Studies conducted in different parts of Amhara region, North West Ethiopia, showed that low practice of feeding children with diversified diet [12, 25]. Study conducted in Northwest Ethiopia in 2016 to assess weaning practice and associated factors in Feres Bete town indicate that about $43.9 \%$ of infants and young children met minimum diversified diet [26].

Community- based cross -sectional study conducted in Northwest Ethiopia in 2015 to assess dietary diversity, meal frequency and associated factors among IYC showed that around $50.4 \%$ of children received minimum meal frequency [12]. The same study conducted in wolaita Sodo town in 2015 showed that $68.9 \%$ of IYC met the minimum meal frequency effect [24].

A healthy care facility based cross-sectional study conducted in Indonesia in 2015 to determine minimum acceptable diet showed that only $47.7 \%$ of children met the minimum acceptable diet. [21]. A result from analysis of 10 Sub Saharan countries' demographic and health surveys between 2010 and 2013 revealed that 18\% of children aged 6-23 months met minimum acceptable diet. The surveys' analysis also suggested that women's empowerment enhance practice of infant and young children MAD. Greater overall empowerment of women was consistently and positively associated with multiple IYCF practices in Mali, Rwanda and Sierra Leone, but negative relationships were found in Benin and Niger. Null or mixed results were observed in the remaining countries [27].

Nutrition education has a great role to improve food security and this enhance to improve nutritional status of children using diversified diet feeding for children $[16,28]$. Mother education is one determinant factor affecting practice of feeding diversified food. Children born from mothers who were well educated and had a secondary level education or higher education had feeding with diversified foods $[12,15]$. Media exposure and income level have positive association with dietary diversity practice. This showed that media exposure has increased the chance infant and young child to feed with diversified food [12]. Children in houses of having high level of income had consumed highly diversified diet than those living in a house of low income level $[15,25]$. 
Involvement of mothers in household decision found to be another determinant factor affecting practice of minimum meal frequency $[12,18]$. As a result children aged 6-23 months will not consume recommended minimum acceptable diet in fasting season. As indicted above variety of studies was conducted and come up with different results of minimum acceptable diet. But none of them considers fasting season in orthodox religion followers.

Therefore this study is needed to assess practice of minimum acceptable diet and to identify associated factors. Although the study area is the area where variety of foods is available, there is no study conducted in Dembecha district on practice of minimum acceptable diet.

\section{Methods}

\section{Study design and setting}

A community-based cross-sectional study was conducted to assess minimum acceptable diet and factors affecting minimum acceptable diet practice among infants and young children aged 6-23 months during fasting season in rural areas of Dembecha district, 2018. Dembecha district is located at $349 \mathrm{~km}$ North West from Addis Ababa, and $203 \mathrm{~km}$ from Bahir Dar, capital city of Amhara region. Greater than 95\% of the population is orthodox religion followers and the rest are other religion followers. The total numbers of children under 5 years is 21, 571 (Dembecha district health office, annual report, 2018). The study was conducted from February 25 to March 27, 2018.

\section{Participants}

Infants and young children aged 6-23 months with mothers / caregivers who were orthodox religion followers and resident of Dembecha district for the past 6 months and available during data collection period were included. Participants were selected using random sampling technique. Among the total kebeles seven kebeles were selected randomly and the total sample size was allocated proportionally. Finally study participants were selected systematically from health post registers. Infants and young children aged 6-23 months with acute illness and other conditions that disturb appetite during data collection period and infants and young children with mothers/caregivers who were seriously ill and cannot give response did not participated in the study. The sample size was calculated using single population proportion considering the proportion of minimum acceptable diet as 12.3, $95 \% \mathrm{CI}, 3 \%$ of margin of error, and $10 \%$ non-response rate. The proportion is taken from study conducted to assess complementary feeding practice in 2015 in Arsi district, southern Ethiopia [23].
The single proportion formula is stated as: $\mathrm{n}=\frac{\left(Z_{2}^{\alpha}\right)^{2} \mathrm{p}(1-p)}{(d)^{2}}$

$$
\begin{aligned}
& \mathrm{n} 1=\frac{(1.96)^{2} \quad 0.123(1-0.123)}{(0.03)^{2}}=460 \\
& \mathrm{~N} 1=\frac{460+460 \times 10}{100}=506
\end{aligned}
$$

The final sample size was 506 .

Where

$\mathrm{P}=$ proportion of minimum acceptable diet

$\mathrm{Za} / 2=$ critical value at confidence interval

$\mathrm{d}=$ margin of error

Random sampling technique was used to select children aged between 6 and 23 months. Infants and young children aged between 6 and 23 months with their mothers were registered in health post. The registration was used as sampling frame (Fig. 1).

\section{Study variable}

Independent variables

The independent variables for this study were maternal/ caregiver's demographic and socio-economic characteristics(ethnicity, income, education, age, occupation, marital status), child age, child sex, birth order, maternal knowledge on minimum acceptable diet practice, training, education given on IYCF, media exposure,(antenatal care, postnatal care, Growth monitoring and promotion service, vaccination service.

Satisfactory exposure to media: Women aged 15-49 years at least once a week who listen to radio, or watch television.

Educated: those parents of infants and young children aged between 6 and 23 months who can read and write.

None educated: parents of infants and young children aged between 6 and 23 months who cannot read and write (Additional file 1).

\section{Dependent variable \\ Minimum acceptable diet was the dependent variable of this study}

Minimum dietary diversity: Proportion of children aged 6-23 months who received four or more food groups from the seven food groups during the previous $24 \mathrm{~h}$.

Minimum meal frequency: Proportion of breastfed and non-breastfed children aged 6-23 months who received solid, semisolid, or soft foods (but also including milk for non-breastfed children). The Minimum frequency will be defined as: at least twice for breastfed infants $6-8$ months, at least three times for breastfed children 9-23 months, and at least four times of foods and 2 feeding of milk 


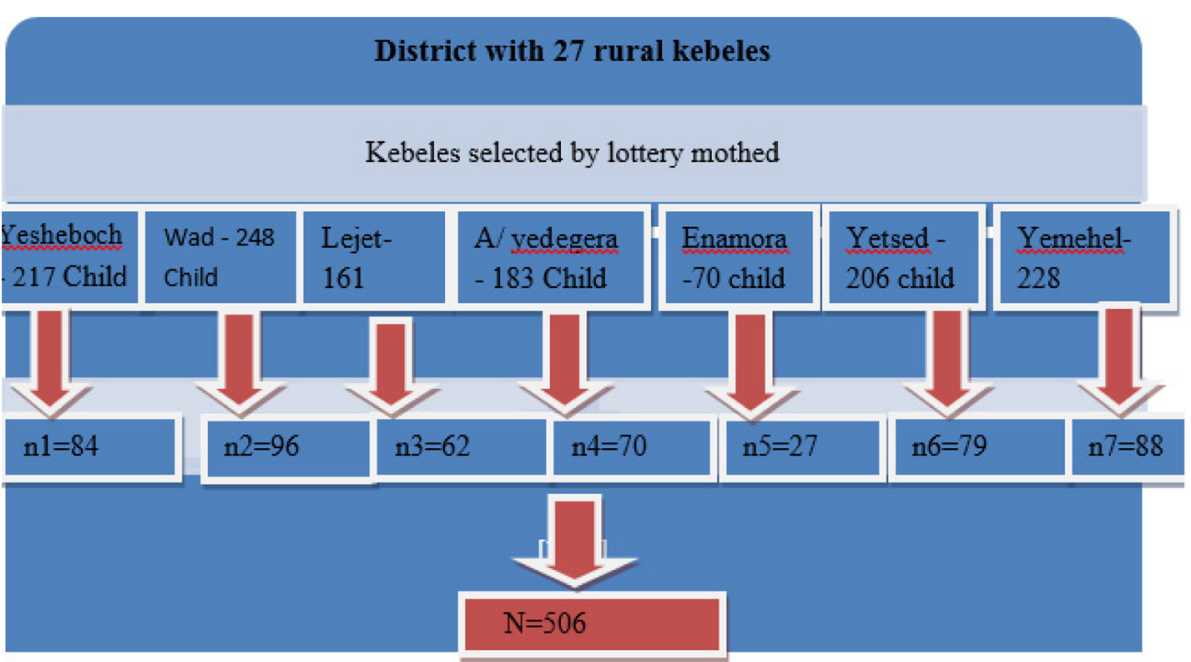

Fig. 1 Schematic presentation of sampling procedure from each selected kebels, Dembecha, North -West Ethiopia, 2018

products for non-breastfed children 6-23 months during the previous $24 \mathrm{~h}$.

Minimum Acceptable diet: Proportion of children 6-23 months of age who receive a minimum acceptable diet (both minimum dietary diversity and the minimum meal frequency) during the previous $24 \mathrm{~h}$.

Milk feeding frequency for non-breasted child is proportion of non-breastfed children 6-23 months of age who receive at least two times of milk feeding (Additional file 1).

\section{Data collection procedures}

Primary data on Practice of minimum acceptable diet, minimum dietary diversity, minimum meal frequency and related factors were collected from mothers or caregivers who had child aged 6-23 months and follower of orthodox religion followers. The data collection tool regarding the various dietary diversity and meal frequency was adopted from WHO IYCF indicator assessment tool with some modification to fit with the context. Household conditions, water source, electricity, livestock, agricultural products, farm land, income were collected as household wealth assets collected by using WFP tools of wealth index. Socio-demographic and other part of data collection tools were adopted from EDHS (2016) and prepared by investigators. Seven health extension workers and two public health officers were participated in data collection. Data were collected using interviewer-administered questionnaire.

\section{Data analysis and quality management}

To assure high quality of the data, Training was given for data collectors and supervisors for $\mathbf{1}$ day. The questionnaire was tested on $5 \%$ of mothers who were not included in the study before the main data collection procedure began to enable the analysis to be conducted in a right way. The collected data was coded, entered and cleaned using Epi-data version 3.1 and was exported to SPSS version 20 for analysis. Frequencies and cross tabulation were calculated to describe the study population in relation to dependent variable. Logistic regression analysis was conducted to show the relationship between dependent and independent variables. Variables with $p$-value less than 0.25 in binary logistic regression were interred to multivariable logistic regression to identify independent effect of independent variables on dependent variables. Principal component analysis was conducted for categorizing household wealth status into three categories; poor, middle and rich.

\section{Result}

Socio-demographic characteristics of study population

A total of 502 infants and young children aged between 6 and 23 months with mother were enrolled in the study that makes a response rate of $99.2 \%$. Among children of mother/caregivers, 259(51.6\%) children were males and 171(34.1\%) were categorized in the age between 18 and 23 months. The mean age of children was $14.5 \pm 5.28$ (SD) months. Of the mother/caregivers of children, 271(54\%) had no education. Among study participants, 487(97\%) mothers were married. About 325(64.7\%) fathers of the children were educated. About 475(94.6\%) of mothers were farmers (Table 1).

\section{Child and mother health care utilization related characteristics}

During pregnancy, 292(58.2\%) of mother received focused ante-natal care service four and above times. Greater than two-third, 407(81.1\%) children were delivered in health facility. Greater than half, 317(63.1\%) of mothers did not received any post natal care. Nearly 
Table 1 Parental level socio demographic characteristic of infants and young children aged 6-23 months, Dembecha, North West Ethiopia, 2018

\begin{tabular}{|c|c|c|c|c|c|}
\hline Characteristics & Frequency(n) & Percentage (\%) & Characteristics & Frequency(n) & Percentage (\%) \\
\hline Mother age(years) & & & Second to third & 146 & 29.1 \\
\hline $15-24$ & 91 & 18.1 & Fourth to fifth & 197 & 39.2 \\
\hline $25-34$ & 295 & 58.8 & Six and above & 72 & 14.3 \\
\hline $35-49$ & 116 & 23.1 & Decision making & & \\
\hline Mother marital status & & & Mothers not involved & 270 & 53.8 \\
\hline Currently married & 487 & 97.0 & Mothers involved & 232 & 46.2 \\
\hline Separated & 10 & 2.0 & Wealth status & & \\
\hline Divorced & 5 & 1.0 & Poor & 150 & 29.9 \\
\hline Ethnicity & & & Middle & 186 & 37.1 \\
\hline Amhara & 502 & 100.0 & Rich & 166 & 33.1 \\
\hline
\end{tabular}

Mother educational status

Not educated

Educated

Father educational status

Non educated

Educated

Mother occupation

Farmer
Housewife
Merchant
Daily worker

Father occupation

Farmer
Employed
Daily worker
Merchant

Number of Under five children

One
Two
Three

Family size the house

Two-four

Five-six

Seven- ten

Age of children

6-11(months)

12-17(months)

18-23 months

Sex of children

Male

Birth order of index child

First
Table 1 Parental level socio demographic characteristic of infants and young children aged 6-23 months, Dembecha, North West Ethiopia, 2018 (Continued)

two-third, 356(70.9\%) of children did not received growth monitoring and promotion service monthly. About $75 \%$ of children were fully vaccinated. From all children, 497(99.0\%) of children were breastfed (Table 2).

\section{Education, knowledge on IYCF and fasting related characteristics}

Greater than two-third, 449(89.4\%) of mothers/caregivers of children had got education on dietary diversity and meal frequency. From mothers of children, 488(97.2\%) mothers had knowledge on feeding children with diversified diet, and 75(14.9\%) of mothers know frequency of feeding based on child age. Greater than half, 265(52.8\%) of mothers were trained on food preparation demonstration with diversified diets. Greater than 334(66.5\%) of children were living in houses where family member fed at any time of fasting season. Less than one third, 81(16.1\%) of children were living with family member who fed animal source foods. About 69(13.7\%) of mothers had satisfactory media exposure (Table 3 ).

\section{Practice of minimum acceptable diet}

From all children, 487(97.0\%) of children received cereals and tubers. About $63 \%$ of children received minimum meal frequency and $49(9.8 \%)$ children fulfill minimum acceptable diet. About $9.8 \%$ of children received minimum dietary diversity (Table 4).

\section{Factors influencing minimum acceptable diet practices} Education status of mother(AOR $=0.22,95 \%$ CI:0.1, 0.48), involvement of mother in decision making ( $\mathrm{AOR}=$ 0.22,95\% CI:0.10,0.48), birth order of index children (AOR $=0.36,95 \% \mathrm{CI}: 0.14,0.94)$, knowledge on feeding frequency ( $\mathrm{AOR}=0.3,95 \% \mathrm{CI}: 0.16,0.58$ ), and institutional delivery $(\mathrm{AOR}=5.13,95 \% \mathrm{CI}: 1.26,20.80)$ were significantly associated with minimum acceptable diet (Table 5). 
Table 2 Child and mother health care related characteristics of children aged between 6 and 23 months, Dembecha, NorthWest Ethiopia, 2018

\begin{tabular}{|c|c|c|}
\hline Characteristics & Frequency(n) & Percentage (\%) \\
\hline \multicolumn{3}{|l|}{ Antenatal service } \\
\hline Fourth and above times & 292 & 58.2 \\
\hline One to three times & 199 & 39.62 \\
\hline No follow up & 11 & 2.2 \\
\hline \multicolumn{3}{|l|}{ Place of delivery } \\
\hline Health facility & 407 & 81.1 \\
\hline Home & 95 & 18.9 \\
\hline \multicolumn{3}{|l|}{ Post natal care } \\
\hline No follow up & 317 & 63.1 \\
\hline Within three to six days & 37 & 7.4 \\
\hline \multicolumn{3}{|c|}{ Growth monitoring and promotion service } \\
\hline No & 356 & 70.9 \\
\hline Yes & 146 & 29.1 \\
\hline \multicolumn{3}{|l|}{ Children vaccination status } \\
\hline Finished & 381 & 75.9 \\
\hline Started & 121 & 24.1 \\
\hline \multicolumn{3}{|l|}{ Current breast feeding status } \\
\hline Breast feeding & 497 & 99.0 \\
\hline Non breast feeding & 5 & 1.0 \\
\hline \multicolumn{3}{|c|}{ Time of starting complementary food } \\
\hline After six months & 226 & 45.0 \\
\hline At six months & 214 & 42.6 \\
\hline Before six months & 62 & 12.4 \\
\hline
\end{tabular}

\section{Discussion}

. The study revealed that about $8.6 \%$ of children received minimum acceptable diet. This result is lower than findings of studies conducted in southern and northern part of Ethiopia which was 12.3 and $12.0 \%$, respectively [23, $29,30]$. But the above mentioned studies determined minimum acceptable diet practice when they studied minimum dietary diversity and minimum meal frequency practiced without consideration of fasting. The difference might be due to high non educated mothers were included in this study but higher number of participants of the above three studies were educated. Difference in data collection period and the above studies include different religion followers who were not in fasting. Finding of this study is compatible with results i.e.,7.3 and 7\% obtained from studies conducted in Nigeria and Ethiopian Demographic and health survey respectively $[9,22]$.

There is no study conducted to show the association between practice of minimum acceptable diet and associated factors in Ethiopia even if the practice was determined when minimum dietary diversity and
Table 3 Education, media exposure, and fasting related characteristics of houses of children aged between 6 and 23 months, Dembecha, North West Ethiopia, 2018

\begin{tabular}{|c|c|c|}
\hline Characteristics & Frequency(n) & Percentage (\%) \\
\hline \multicolumn{3}{|l|}{ Read newspapers and magazine } \\
\hline No & 486 & 96.8 \\
\hline One and above times a week & 16 & 3.2 \\
\hline \multicolumn{3}{|c|}{ Education on dietary diversity and meal frequency } \\
\hline Yes & 449 & 89.4 \\
\hline No & 53 & 10.6 \\
\hline \multicolumn{3}{|l|}{ Food cooking demonstration training } \\
\hline Yes & 265 & 52.8 \\
\hline No & 237 & 47.2 \\
\hline \multicolumn{3}{|l|}{ Media exposure } \\
\hline Unsatisfactory & 433 & 86.3 \\
\hline Satisfactory & 69 & 13.7 \\
\hline \multicolumn{3}{|l|}{ Knowledge on child feeding } \\
\hline On dietary diversity & 488 & 97.2 \\
\hline On feeding frequency & 75 & 14.9 \\
\hline \multicolumn{3}{|l|}{ Reason for not feed animal source food } \\
\hline Contaminate feeding utensils & 143 & 28.4 \\
\hline Not necessary for children & 48 & 9.5 \\
\hline Due to fasting & 29 & 5.7 \\
\hline \multicolumn{3}{|l|}{ Family member feeding practice in fasting } \\
\hline Not consume animal source foods & 421 & 83.9 \\
\hline Consume at any time in fasting & 334 & 66.5 \\
\hline Not consume at any time in fasting & 168 & 33.5 \\
\hline Consume animal source foods & 81 & 16.9 \\
\hline
\end{tabular}

minimum meal frequency were assessed. Therefore it is not possible to compare factors associated with minimum acceptable diet practice in this study with other study findings. Mother educational status was significantly associated with minimum acceptable diet. According to this study children born from mother who had education were $56 \%$ more likely to receive minimum acceptable diet when compared with children born from non-educated mother(AOR = 0.44,95\%CI:0.23, 0.86). This showed that education enables mothers/caregivers to know benefits of practice of dietary diversity and feeding frequency and minimum acceptable diet practice in infants and young children aged between 6 and 23 months was adequate.

This study found that birth order of the index child is one of the predictors of practice of minimum acceptable diet. Children born in first order $(A O R=$ 0.36, 95\%CI: $0.16,0.58$ ), and second to fourth order $(\mathrm{AOR}=0.28,95 \% \mathrm{CI}: 0.14,0.54)$ were 64 and $72 \%$ less likely to receive minimum acceptable diet when 
Table 4 Practice of minimum acceptable diet, minimum dietary diversity and minimum meal frequency among children aged between 6 and 23 months, Dembecha, North - West Ethiopia, 2018

\begin{tabular}{lll}
\hline Food groups & Frequency(n) & Percentage (\%) \\
\hline Cereals \& roots & 487 & 97.0 \\
Legumes \& nuts & 409 & 81.5 \\
Other fruits and vegetables & 257 & 51.2 \\
Vitamin A rich fruits and vegetables & 51 & 10.2 \\
Eggs & 45 & 9.0 \\
Milk \& its products & 27 & 5.4 \\
Flesh food & 1 & 0.2 \\
Minimum dietary diversity & & \\
Non adequate & 453 & 90.2 \\
Adequate & 49 & 9.8 \\
Minimum meal frequency & & \\
Adequate & 319 & 63.5 \\
Non adequate & 182 & 36.3 \\
Minimum acceptable diet & & \\
Non adequate & 459 & 91.4 \\
Adequate & 43 & \\
\hline
\end{tabular}

compared with children born in above fourth order respectively. As parity of mother's increases, there is high exposure to practice and information on diversified diet preparation and feeding frequency that enables children to meet minimum acceptable diet. Another important factor significantly associated with minimum acceptable diet during fasting season was mothers' participation in household decision making. Children born from mothers involved in household decision making were $78 \%$ more likely to receive minimum acceptable diet when compared with children of mothers who were not involved in decision making $(\mathrm{AOR}=0.22$. $95 \% \mathrm{CI}: 0.1,0.48)$. involvements of mothers in decision making in the household enables mothers to access money for purchasing foods which increases availability of some foods like egg and fruits and vegetables in the household. Then children would meet minimum acceptable diet. Delivery in health facility found to be significant associated with practice of minimum acceptable diet. Children born in health facility were 5 times more likely to receive minimum acceptable diet than who were born at home $(\mathrm{AOR}=$ 5.13, 95\%CI: 1.26, 20.8). Mother counseling on child feeding after delivery in health facility increases knowledge of mother on dietary diversity and feeding frequency.

Other factor associated with minimum acceptable diet feeding practice was previous knowledge on feeding frequency based on age. Children whose mothers or caregiver's did not have knowledge on feeding frequency $(\mathrm{AOR}=0.3,95 \% \mathrm{CI}: 0.16,0.58)$ were $70 \%$ less likely to receive minimum acceptable diet when compared to children of mothers who had knowledge of feeding frequency. This indicate that knowing feeding frequency based on child age leads the mother/ care givers to give diet timely throughout all seasons.

Presence of family member who fed animal source foods found to be significantly associated with practice of minimum acceptable diet. Children lived with family member who consumed animal source foods were 5 times more likely received minimum acceptable diet than those children who were living in houses with no family member who could consume animal source food$\mathrm{s}(\mathrm{AOR}=5.64,95 \% \mathrm{CI}: 2.8,11.37)$. This showed that animal source foods might be prepared and its availability would be increased if consumer of this food group was present in the house. This would enable the child to consume animal source foods and this increases the number of food groups the child could fed.

Only $9.8 \%$ of children received minimum dietary diversity which is lower than results of similar study conducted in North West Ethiopia [31]. The difference might be due to participants' residential difference. Studies conducted in southern part of Ethiopia that is 23.3\% of children received foods from four and above food groups [14]. The difference might be due to high purchasing capacity and greater than $60 \%$ of mothers of the children were protestant religion followers who are not participated in fasting season. Due to this reason the practice of dietary diversity is high in the above study. Other study conducted in North West Ethiopia showed that $12.6 \%$ of children received minimum dietary diversity feeding which is greater than the result of this study [12]. The difference is due to educational status difference. About $58 \%$ of mothers had education in the above study, but $46 \%$ of mothers included in this study were educated. The result of this study showed that the practice of dietary diversity is higher than result of study conducted in other area of North West Ethiopia which was $8.5 \%$ [25]. The difference might be due to recent expansion of nutritional programs working in child nutrition that enables improvement in dietary diversity in rural area. In this study $63.5 \%$ of children fulfill the WHO minimum meal frequency criteria in $24 \mathrm{~h}$. The result is lower than results of two studies conducted in southern part of Ethiopia with results of 67.3 and $68.9 \%$ respectively $[23,24]$. The difference might be due to difference in religion status of mothers of children. But the result is higher than result of studies conducted in Ethiopia with result of $50.5 \%$, and in North West Ethiopia with a result of $50.4 \%[12,29]$. The difference in results might be due to presence of low attention for child feeding in previous year. 
Table 5 A bivariate and multivariate logistic regression output showing factors associated with minimum acceptable diet practice among children aged between 6 and 23 months, Dembecha, North West Ethiopia, 2018

\begin{tabular}{|c|c|c|c|c|c|}
\hline \multirow[t]{2}{*}{ Characteristics } & \multicolumn{5}{|c|}{ Minimum acceptable diet } \\
\hline & Inadequate N (\%) & Adequate N(\%) & COR (95\%) & AOR (95\%) & $P$-Value \\
\hline \multicolumn{6}{|l|}{ Mother education } \\
\hline Educated & $207(89.6)$ & $24(10.4)$ & 1 & 1 & 1 \\
\hline Non educated & $252(93.0)$ & $19(7.0)$ & $0.65(0.35,1.22)$ & $0.44(0.23,0.86)$ & $0.01^{*}$ \\
\hline \multicolumn{6}{|l|}{ Father education } \\
\hline Educated & $293(90.2)$ & $32(9.8)$ & 1 & 1 & 1 \\
\hline Not educated & $166(93.8)$ & $11(6.2)$ & $0.60(0.29,1.23)$ & $0.7(0.32,1.57$ & 0.4 \\
\hline \multicolumn{6}{|l|}{ Decision making in house } \\
\hline Mothers involved & $198(85.3)$ & $34(14.7)$ & 1 & 1 & 1 \\
\hline Mothers not involved & $261(96.7)$ & $9(3.3)$ & $0.2(0.09,0.43)$ & $0.22(0.1,0.48)$ & $0.0^{*}$ \\
\hline \multicolumn{6}{|l|}{ Birth order of index child } \\
\hline First Fifth and above & $130(86.7)$ & $20(13.3)$ & 1 & 1 & 1 \\
\hline Second to fourth & $248(93.6)$ & $17(6.4)$ & $0.45(0.23,0.88)$ & $0.28((0.14,0.54)$ & $0.00^{*}$ \\
\hline First & 81 (931) & $6(6.9)$ & $0.48(0.18,1.25)$ & $0.36(0.14,0.94)$ & $0.036^{*}$ \\
\hline \multicolumn{6}{|l|}{ Place of delivery } \\
\hline Home & $94(98.9)$ & $1(1.1)$ & 1 & 1 & 1 \\
\hline Health facility & $365(89.7)$ & $42(10.3)$ & $10.82(1.47,79.61)$ & $5.13(1.26,20.8$ & $0.02^{*}$ \\
\hline \multicolumn{6}{|l|}{ Knowledge on MF } \\
\hline Yes & $62(82.7$ & $13(17.3)$ & 1 & 1 & 1 \\
\hline No & $397(93.0)$ & $30(7.0)$ & $0.36(0.17,0.72)$ & $0.3(0.16,0.58)$ & $0.00^{*}$ \\
\hline \multicolumn{6}{|l|}{ Education given on MAD } \\
\hline Yes & $407(90.6)$ & $42(9.4)$ & 1 & 1 & 1 \\
\hline No & $52(98.1)$ & $1(1.9)$ & $0.18(0.03,1.38)$ & $0.59(0.07,5.12)$ & 0.63 \\
\hline \multicolumn{6}{|c|}{ Food preparation demonstration training } \\
\hline Yes & $232(87.5)$ & $33(12.5)$ & 1 & 1 & 1 \\
\hline No & $227(95.8)$ & $10(4.2)$ & $0.31(0.15,0.64)$ & $0.48((0.22,1.05)$ & 0.06 \\
\hline \multicolumn{6}{|c|}{ Meeting of women health development army } \\
\hline No & $428(92.0)$ & $37(8.0)$ & 1 & 1 & 1 \\
\hline Yes & $31(83.8$ & $6(16.2)$ & $2.24(0.88,5.71)$ & $0.69(0.21,2.27)$ & 0.54 \\
\hline \multicolumn{6}{|l|}{ Media exposure } \\
\hline Satisfactory & $67(97.1)$ & $2(2.9)$ & 1 & 1 & 1 \\
\hline Not satisfactory & $392(90.5)$ & $41(9.5)$ & $3.5(0.83(14.83)$ & $1.23(0.52,2.87)$ & 0.65 \\
\hline \multicolumn{6}{|c|}{ Family member who ate at any time in fasting season } \\
\hline Yes & $299(89.5)$ & $35(10.5)$ & 1 & 1 & 1 \\
\hline No & $160(95.0)$ & $8(5.0)$ & $0.43(0.19,0.94)$ & $0.78(0.32,1.9)$ & 0.59 \\
\hline \multicolumn{6}{|c|}{ Family member who consumed animal source foods } \\
\hline No & $404(96.0)$ & $17((4.0)$ & 1 & 1 & 1 \\
\hline Yes & $55(67.9)$ & $26(32.1)$ & $11.23(5.73,22.0)$ & $5.64(2.8,11.37)$ & $0.00^{*}$ \\
\hline \multicolumn{6}{|c|}{ Believe on not feed child animal source foods } \\
\hline Not believe & $246(87.2)$ & $36(12.8)$ & 1 & 1 & 1 \\
\hline Believe & $213(96.8)$ & $7(3.2)$ & $0.23(0.098,0.52)$ & $0.53(0.21,1.32)$ & 0.17 \\
\hline
\end{tabular}

Notice: * significant associated, COR Crude odds ratio, AOR Adjusted odds ratio. PV: $p$-value 


\section{Conclusion}

Minimum acceptable die practice in infants and young children aged between 6 and 23 months is low. Educational status of mother, involvement of mother in decision making, First birth order of index child, second to fourth birth order of index child, knowledge on feeding frequency were factors negatively associated with minimum acceptable diet. Delivery in health facility, and presence of family member who fed animal source foods during fasting were positively associated with minimum acceptable diet. Strengthening mothers' education on acceptable child feed practice and working with religion leaders to increase knowledge of mother on child feed practice during fasting season. Conduct study with strong study design in wide area to determine minimum acceptable diet and factor associated with minimum acceptable diet practice.

\section{Additional file}

Additional file 1: Questionnaire prepared for assessment of minimum acceptable diet among Infants and young children aged between 6-23 months in Fasting season, Dembecha, North -West Ethiopia, 2018 (DOCX $70 \mathrm{~kb}$ )

\section{Abbreviations \\ ANC: Antenatal care; DHS: Demographic and Health Survey; EDHS: Ethiopian Demographic and Health Survey; HSDP: Health Sector Development Plan; IYC: Infant and young child; IYCF: Infant and young child feeding: IYCMAD: Infant and young child minimum acceptable diet; IYCMDD: Infant and young child minimum dietary diversity; MAD: minimum acceptable die; MDD: minimum dietary diversity; MDG: millennium Development goal; MMF: minimum meal frequency; NGO: Non-Governmental Organization; PNC: post natal care; WFP: World Food Program; WHO: World Health Organization}

\section{Acknowledgements}

We would like to thank Debre Markos University collage of health science for providing ethical clearance, data collectors, supervisor and study participants.

\section{Funding}

No funding was obtained for this study. Covered by investigators.

\section{Availability of data and material}

The datasets used and/or analyzed during the current study are available from the corresponding author on reasonable request.

\section{Author contributions}

Conceptualization: EM. Formal analysis: EM GA WW HT. Development or design of methodology: EM GA WW HT. Entering data into computer software: EM HT. Supervision: EM GA WW HT Validation: EM GA WW HT writing original draft: EM GA WW HT. Writing review \& editing: EM GA WW HT. All authors read and approved the final manuscript.

\section{Ethics approval and consent to participate}

Ethical clearance was obtained from Debre Markos University, College of health science ethical review committee and official letter was written to Dembecha District Health Office and permission letter was obtained from the Dembecha district health office. Verbal consent was taken from each participant after the purpose of study was explained. This is because the study was conducted in rural part of Dembecha district in which written consent is impossible due to presence of uneducated mothers/caregivers. This is approved by ethical clearance committee of Debremarkos University. Confidentiality was maintained by omitting their name and other personal identification.
Consent for publication

Not applicable.

\section{Competing interests}

The authors have declared that no competing interests exist.

\section{Publisher's Note}

Springer Nature remains neutral with regard to jurisdictional claims in published maps and institutional affiliations.

\section{Author details}

'Dembecha Health Center, WEST Gojam Zone Health Department, Dembecha, Ethiopia. ${ }^{2}$ Department of Nurse, College of Health Sciences, Debre Markos University, P.O. Box 269, Debre Markos, Ethiopia. ${ }^{3}$ Lecturer of Nutrition, Department of Human Nutrition and Food Sciences, College of Health Science, Debre Markos University, P.O. Box 269 Debre Markos, Ethiopia.

Received: 30 August 2018 Accepted: 29 January 2019

Published online: 27 February 2019

\section{References}

1. Organization WH. Infant and young child feeding: model chapter for textbooks for medical students and allied health professionals. Infant and young child feeding: model chapter for textbooks for medical students and allied health professionals 2009

2. Victora CG, Adair L, Fall C, Hallal PC, Martorell R, Richter L, et al. Maternal and child undernutrition: consequences for adult health and human capital. Lancet. 2008;371(9609):340-57.

3. Black RE, Allen LH, Bhutta ZA, Caulfield LE, De Onis M, Ezzati M, et al. Maternal and child undernutrition: global and regional exposures and health consequences. Lancet. 2008;371(9608):243-60.

4. Ethiopia FDRo. National Nutrition program Guideline. Addis Ababa, Ethiopia2015.

5. WHO U, USAID F, AED U. Indicators for assessing infant and young child feeding practices part 2: measurement. Geneva: The World Health Organization; 2010.

6. WHO U, USAID, FANTA, AED, UC DAVIS, and IFPRI. Geneva. Indictors for assessing infant and young child feeding practices part III:. 2010.

7. Organization WH. Indicators for assessing infant and young child feeding practices: part 1: definitions: conclusions of a consensus meeting held 6-8 November 2007 in Washington DC, USA. 2008.

8. Black RE, Victora CG, Walker SP, Bhutta ZA, Christian P, De Onis M, et al. Maternal and child undernutrition and overweight in low-income and middle-income countries. Lancet. 2013;382(9890):427-51.

9. Agency CS. Ethiopian demographic and health survey. Addis Ababa, Ethiopia2016.

10. Ethiopia CSAo. Ethiopia Demographic and Health survey 2011. Addis Ababa2013.

11. Disha A, Tharaney M, Abebe Y, Alayon S, Winnard K. Factors associated with infant and young child feeding practices in Amhara region and nationally in Ethiopia: analysis of Ethiopia demographic and health surveys 2005 and $2011 ; 2015$.

12. Beyene M, Worku AG, Wassie MM. Dietary diversity, meal frequency and associated factors among infant and young children in Northwest Ethiopia: a cross-sectional study. BMC Public Health. 2015;15(1):1007.

13. Dewey K. Guiding principles for complementary feeding of the breastfed child; 2002.

14. Gatahun A, Abyu M. Dietary diversity feeding practice and determinants among children aged 6-23 months in Kemba Woreda, southern Ethiopia implication for public health intervention. Nutrition \& Food Sciences 2015.

15. Solomon D, Aderaw Z, Tegegne TK. Minimum dietary diversity and associated factors among children aged 6-23 months in Addis Ababa Ethiopia. Int J Equity Health. 2017;16(1):181.

16. USAID. Global health E-learning Center-Program and course catalogue. Washington DC2012.

17. Aemro M, Mesele M, Birhanu Z, Atenafu A. Dietary diversity and meal frequency practices among infant and young children aged 6-23 months in Ethiopia: a secondary analysis of Ethiopian demographic and health survey 2011. J Nutri Metabol. 2013;2013. 
18. Patel A, Pusdekar Y, Badhoniya N, Borkar J, Agho KE, Dibley MJ. Determinants of inappropriate complementary feeding practices in young children in India: secondary analysis of National Family Health Survey 2005-2006. Matern Child Nutri. 2012:8:28-44.

19. Senarath UGS, Jayawickrama H, Siriwardena I, Dibley MJ. Determinants of inappropriate complementary feeding practices in young children in Sri Lanka: secondary data analysis of demographic and health survey 2006-2007. Matern Child Nutri. 2012;8(s1):60-77.

20. Joshi N, Agho KE, Dibley MJ, Senarath U, Tiwari K. Determinants of inappropriate complementary feeding practices in young children in Nepal: secondary data analysis of demographic and health survey 2006. Matern Child Nutri. 2012;8:45-59.

21. Dewanti A.J. Muslimatus S. IND, and Khusun H.; . minimum acceptable diet and factors related among children aged 6-23 months in bekasi municipality west java province Indonesia . Indonesia, 2015: Vol 17, Issue 2 2015; Page No. (415-421). . Asian Journal of microbiology, Biotechnology \& Environmental Sciences Paper. 2015;17(2):415-421.

22. Udoh EE, Amodu OK. Complementary feeding practices among mothers and nutritional status of infants in Akpabuyo area Cross River State Nigeria. SpringerPlus. 2016;5(1):2073.

23. Kassa T, Meshesha B, Haji Y, Ebrahim J. Appropriate complementary feeding practices and associated factors among mothers of children age 6-23 months in southern Ethiopia 2015. BMC pediatrics. 2016;16(1):131.

24. Mekonnen TC, Workie SB, Yimer TM, Mersha WF. Meal frequency and dietary diversity feeding practices among children 6-23 months of age in Wolaita Sodo town Southern Ethiopia. J Health, Popul Nutri. 2017;36(1):18.

25. Gessese D, Bolka H, Alemu Abajobir A, Tegabu D. The practice of complementary feeding and associated factors among mothers of children 6-23 months of age in Enemay district, Northwest Ethiopia. Nutri Food Sci. 2014;44(3):230-40.

26. Bewket Zeleke L, Welday Gebremichael M, Mehretie Adinew Y, Abebe Gelaw K. Appropriate weaning practice and associated factors among infants and young children in Northwest Ethiopia. J Nutri Metabol. 2017;2017.

27. Na M, Jennings L, Talegawkar SA, Ahmed S. Association between women's empowerment and infant and child feeding practices in sub-Saharan Africa: an analysis of demographic and health surveys. Public Health Nutr. 2015; 18(17):3155-65.

28. Bank W. From agriculture to nutrition: pathways, synergies, and outcomes. Agricultural and Rural Development Notes 2007;45363.

29. Roba KT, O'Connor TP, Belachew T, O'Brien NM. Infant and young child feeding (IYCF) practices among mothers of children aged 6-23 months in two agroecological zones of rural Ethiopia. Int J Nutr Food Sci. 2016;5(3):185-94.

30. Mekbib E, Shumey A, Ferede S, Haile F. Magnitude and factors associated with appropriate complementary feeding among mothers having children 6-23 months-of-age in northern Ethiopia; a community-based crosssectional study. J Food Nutr Sci. 2014;(2, 2):36.

31. Kumera G, Tsedal E, Ayana M. Dietary diversity and associated factors among children of orthodox Christian mothers/caregivers during the fasting season in Dejen District, north West Ethiopia. Nutri Metabol. 2018;15(1):16.

\section{Ready to submit your research? Choose BMC and benefit from:}

- fast, convenient online submission

- thorough peer review by experienced researchers in your field

- rapid publication on acceptance

- support for research data, including large and complex data types

- gold Open Access which fosters wider collaboration and increased citations

- maximum visibility for your research: over $100 \mathrm{M}$ website views per year

At BMC, research is always in progress.

Learn more biomedcentral.com/submissions 